\title{
Ethical concerns for maternal surrogacy and reproductive tourism
}

\author{
Raywat Deonandan, ${ }^{1}$ Samantha Green, ${ }^{2}$ Amanda van Beinum ${ }^{3}$
}

\begin{abstract}
Reproductive medical tourism is by some accounts a multibillion dollar industry globally. The seeking by clients in high income nations of surrogate mothers in low income nations, particularly India, presents a set of largely unexamined ethical challenges. In this paper, eight such challenges are elucidated to spur discussion and eventual policy development towards protecting the rights and health of vulnerable women of the Global South.
\end{abstract}

\section{INTRODUCTION}

Reproductive tourism (RT) is an emerging, ethically problematic phenomenon at the interface between commerce and clinical care. Defined as the travelling of [clients] from their country of residence to another country in order to receive a specific treatment or to exercise personal reproductive choice', it typically involves the seeking of assisted reproductive technologies (ARTs), including in vitro fertilisation, intracytoplasmic sperm injection, preimplantation genetic diagnosis, gamete donation and maternal surrogacy. While the this accelerating industry has loci in the USA, Eastern Europe, Latin America and Southeast Asia, India is thought to be the world's greatest provider of surrogate mothers; their industry is likely worth $\$ 500$ million $^{2}$ to $\$ 2.3$ billion. $^{3}$

When the client is from a high income country and the jurisdiction providing the service is a low or middle income country (LMIC), the opportunity for exploitation is great. This is particularly true when maternal surrogacy is involved, as it most blatantly abuts issues of female autonomy and reproductive rights. Generally, clients' motivations for travel for ART is a combination of legal and pricing restrictions in the source countries and the openness of services in destination countries. ${ }^{4}$ The motivation for surrogate mothers in LMICs has not been well studied, but is thought to be primarily financial; Indian surrogates can make as much as US $\$ 6000 .^{5}$

Previous examinations of RT ethics have identified the exploitation and objectification of women, the welfare of ART-produced children, and the unregulated state of the industry as causes for concern. $^{6-11}$ In this paper, we seek to identify the key ethical themes within the surrogacy component of the global RT industry most worthy of policy attention.

\section{METHODS}

Through literature review, consultation with clinicians and policymakers, and consideration of RT within the larger context of international health and development, we identified the key issues raised. We employed a Western liberal ethical framework, with an acknowledgement of the framework's limitations for, as stated by Widdows, ${ }^{12}$ it may be inadequate for application to all of medical tourism due to its overindividualistic nature. However, it is a useful first step in examining the competing mores of RT.

\section{RESULTS}

We identified eight ethical issues specific to the engaging of surrogate mothers from LMICs.

\section{DISCUSSION \\ Robustness of informed consent}

Traditionally, informed consent involves the communication of medical risks and benefits. ${ }^{13}$ Its challenges typically concern the quality and clarity of communication and the avoidance of coercion, subtle or overt. ${ }^{14}$ Given surrogates' tendency to be poor, illiterate and possibly susceptible to the neocolonial motivator of an impressive medical authority figure, one must consider how best to assess the extent to which consent can be coerced simply through a clinician's bearing, accent, caste/class or social power.

Ultimately, this discourse concerns the tension between the individual rights of the surrogate and client to negotiate a commercial relationship, and the responsibilities of policymakers, clinicians and civil society to ensure that the industry is not simply a new face of neo-colonial exploitation. The legacy of colonialism is difficult to disentangle from the experience of RT, especially when the destination country is a former European colony, such as India. Perspectives from Africa suggest that illiteracy and a colonial heritage combine to make informed consent problematic. ${ }^{15}$ The same forces apply in India, where an authority figure modelled on an image of Western power, such as a doctor, is afforded automatic deference.

Additionally, the medical informed consent model fails to consider that downstream social risks and impacts must also be communicated; simply expressing the biological risks may not be sufficient to attain defensible consent. Examples include surrogates' risk of social shunning; ${ }^{16}$ it is possible that a surrogate's community, spouse or family may object to her carrying the child of a man other than her husband or the child of a homosexual couple. Media reports suggest that surrogates can be accused of adultery and face being ostracised by their community. ${ }^{17}$ Arguably, 
the risk of shunning and other social risks should be included within the process of acquiring the informed consent.

Even if all manner of risk is included, one concern that arises from informed consent is that an individualistic legal system might conclude that an expression of autonomy includes the right to exercise that autonomy to allow one's own exploitation. In other words, the legal expression of informed consent gives the surrogate a better sense of the real risks she will face and provides legal cover for the clinicians and client who may then place her in a position of danger. Informed consent can be used to vitiate legal responsibility, which is often misunderstood as a vitiation of moral responsibility, as well. This sentiment may evoke a complex debate about the conditions of political liberalism, and we wish to acknowledge that a plethora of views exist on this matter.

Informed consent may be the base upon which a new ethical framework for RT must be built. The present model holds that so long as a surrogate expresses understanding of her risks, and so long as the clinician, client and state make a reasonable effort to fully convey those risks without a sense of overt coercion-and reasonably believe that their words were understood-then the procedure, however risky, is sufficiently ethical.

However, three factors confound that perspective. First, as mentioned, social risks and emotional risks can be as damaging as physical ones; communication of all kinds of risk, not just the biological, is required. Second, since many LMIC surrogates are poor and possibly illiterate, the economic and power differential between surrogate and clinician, or client, is extreme. In such instances, the traditional threshold for accepting consent may not be high enough. Additional measures are required to better ensure complete communication of risk, complete understanding of risk and appropriate balance of real risk against the lure of potentially significant compensation.

Third, in a cross-cultural transaction, individual autonomy may need to give way to the possibility of including the voices of other stakeholders. The surrogate's existing children, husband, greater family and indeed her neighbours may have a stake in the decision she makes. In the new bioethics that may emerge from RT, the individualistic elements that presently characterise medicine's legal and ethical practice may need to be enhanced by some context- and community-based elements if informed consent is to have continued meaning.

\section{Custody rights}

A surrogate's custodial rights vary between jurisdictions. For example, Michigan's Surrogate Parenting Act $^{18}$ does not allow for recognition of surrogate parentage contracts, meaning that the surrogate has strong rights regarding potential custody. Meanwhile, Indian law is robust in recognising the legality of the surrogate contract, ${ }^{19}$ thus providing more assurance for the RT client.

Arguably, a nation with laws disfavouring the surrogate and favouring the client is a more attractive destination for an RT client seeking the fewest legal barriers. As RT grows in economic importance, the extent to which a nation's custody and adoption laws are influenced by the industry's needs must be considered. Both source and destination societies should be on guard for the creeping in of commercial interest into the phrasing of laws meant to define essential societal values. We argue that the definition of parenthood and its associated familial rights are an essential reflection of a society's character, and this is therefore the essence of the problematic nature of variable custody rights: the uncertain extent to which commercial expedience may falsely portend to reflect the actual values of the society in question.

\section{Quality of surrogate care}

While it is likely that different clinics embrace different models of care, it remains uncertain to what extent a surrogate's health is maintained beyond her gestational role. It is reasonable to expect the client to fund the nutritional requirements of the surrogate, as her physical health relates directly to the health of the child she gestates. But her needs probably extend beyond the physical. What of her social and mental health? If her role as a surrogate requires her to change her diet and perhaps alter her daily physical activities, it is possible that these changes impart an emotional impact. Moreover, her regular domestic familial duties may be affected by her role as a surrogate; the extent to which the stresses of these dual roles are dealt with by the client and clinician constitute an ethical question.

Unfortunately, it is difficult to find concrete examples of actual transgressions in this category. We found no studies of the care and home conditions of surrogates in LMICs. But, it is foreseeable that a commercial model that employs a surrogate as a means for the creation of a child will have financial disincentives for expending resources on her beyond that which is necessary to produce a healthy child.

\section{Limits of surrogate care}

While the surrogate's medical health is important during pregnancy, there is a moral argument for assuring that that care extends beyond the delivery. Given the likelihood of postpartum injury (or depression), it remains uncertain who is ultimately responsible for assuring that a surrogate is given sufficient care to recover from such conditions. Postpartum injury is the direct result of a process begun by clinician for the purpose of achieving a biological product for the client. It can be argued that since such injury is a foreseeable consequence of the overall process, then both avoiding and repairing such injury is the logical responsibility of all agents involved, and not just of the surrogate herself.

A corollary is the question of the economic incentives for maintaining a surrogate's health well past delivery. A woman with proven gestational ability is an asset to a clinic that employs surrogates; thus, it is rational for that clinic to ensure her continued health and gestational capacity. It is interesting that an economic argument would perhaps be more compelling than an altruistic one for ensuring proper extended care for a postdelivery surrogate.

\section{Remuneration}

A likely motivator for an RT client is reduced cost. But while remuneration for an LMIC surrogate is probably above what she would otherwise earn, it is below the global average. The concept of 'fair trade international surrogacy' ${ }^{10}$ addresses the choices that the client can make to improve the probability of an ethical transaction, but could be further enhanced by including an argument for either voluntary or compulsory standardisation of global surrogacy fees, thus reducing global the economic gradient.

Humbyrd's 'fair trade surrogacy' model seeks to apply the lessons of 'fair trade coffee' to RT. In short, pricing would be set to 'a fair price in the regional or local context'. ${ }^{10}$ The 'fair trade' label would presumably then be used to market the service to more equity-minded clients. While paying a 'fair price' does not necessarily abrogate all ethical concerns about 
exploitation, it does serve to address one small variable in equation, the amount of money received by the allegedly exploited party. This approach is in line with common practise in civil justice, wherein tort is addressed through financial recompense.

\section{Multiple embryo transfers and abortion}

Selective reduction is not an uncommon occurrence in $\mathrm{ART}^{20}$ especially where multiple embryos are desired. The extent to which a surrogate is encouraged to accept multiple embryos, to maximise the probability of a successful implantation and thus reduce costs to the client, is a factor influencing both the autonomy of the surrogate and the nature of her informed consent. Related is the possibility for a selective reduction abortion, done for several medically defensible reasons. It remains unknown whether surrogates from conservative cultures are either aware or culturally responsive to this likelihood.

A multiple pregnancy is a dangerous medical condition that is avoided by fertility doctors in the West. ${ }^{21}$ Yet, it is attractive as a cost saving measure, since more transfers raise the chance of a pregnancy and reduces the number of attempts needed to become pregnant. ${ }^{22}$ Coercion of the surrogate, to reduce costs, becomes a possibility.

\section{Medical advocacy}

The most blatant ethical pitfall is the model for clinical supervision: the clinic receives payment from one party (the client) and performs a procedure on a second party (the surrogate). In other words, one entity represents both the paying client and the paid surrogate. Several stakeholders, with potentially competing interests, are at play: the client, her spouse, the surrogate and, of course, the child resulting from the process.

The potential is great for conflicts of interest, especially when clinical decisions must be made that weigh monetary cost against the health of the surrogate. In such scenarios, the cynic would suspect that the interests of the paying client will prevail, even to the detriment of the health of the surrogate. At the very least, the incentive for such favouritism is financial, whereas the sole disincentive is moral.

In absence of an independent advocate, the surrogate is essentially being treated as an independent contractor who must bring her own expertise and resources to the business relationship. The clinic, in this sense, acts as an arbitrator through which a commercial transaction takes place. Beyond the clinic's legal and professional requirements of good care, the surrogate's interests are limited to those which she manages to negotiate a priori.

The ethics at play are business ethics, not medical ethics. In business ethics, so long as full disclosure and fair play are in effect, all actors must be content with the scenario negotiated before the actual act of business; and all actors are expected to consider only their own needs, not the needs of the other party. The arbitrator's role is to enforce fairness. But in medical ethics, a clinic's role is to provide continual good care, always acting in that patient's best interests. A clinic is not equipped legally or experientially to act in the role of arbitrator nor is it empowered to do so via the tradition of medical ethics.

After informed consent, herein lies the second major challenge faced by RT: to find a comfortable space between medicine and commerce using a hybrid ethical framework that refuses to compromise the essential role of a clinician, which is to always act in the best interests of the person under care. One solution is to assure that each surrogate is given the support of a separate medical advocate to counterbalance the great power held by the client to influence decisions made about the surrogate's health. The evolution of such an advocacy model has yet to begin.

\section{Exploitation of the poor}

When one hears of travellers from rich countries paying very poor women in an LMIC to carry their babies, it is difficult not to wonder if this is a case of exploitation. The tension is between the libertarian view of free choice versus the sense that choice may be economically coerced. The fundamental question is: is it moral to leverage poverty to receive a service that might not otherwise be offered?

Similar arguments have been put forward for condemning prostitution, especially among impoverished peoples. The assumption underlying this condemnation is that no one would choose to sell sex, or to rent their wombs, if there were any other economic options.

This is the heart of the Western liberal ethical framework to consider the individual's right of unhindered choice to be sacrosanct. In other words, so long as the provider of the servicewhether it is a womb or sex for money-does so of her own free will, then the transaction is likely ethical. But it is the very nature of the choice that is philosophically problematic: can there be genuine choice between two options if one of the options is profoundly unbearable, such as starvation? In RT, it is the extent to which financial need dictates the surrogate's choice to participate that remains in question, as well as whether that extent really is a rational metric to employ when making an ethical determination.

Instances of altruistic surrogacy exist, especially in nations that prohibit paid surrogacy. So the temptation is to assess each instance of cross-border surrogacy on an individual basis, which is both impractical and ultimately misleading, since there are larger population observations that can shed light on the phenomenon. For instance, Indian surrogates are seemingly universally poor, ${ }^{6}$ suggesting that their prime motivator is indeed economic, not altruistic.

If financial need is the basis for surrogates' eagerness to participate, is it then ethical to use this need to encourage participation? Conversely, is it ethical to deny an impoverished prospective surrogate the opportunity to lift her family out of poverty simply because one decides that financial need is an inappropriate lever? Is that, too, not a kind of neo-colonial arrogance?

To use someone's desperation to leverage an outcome or behaviour that that person would not otherwise offer is indeed exploitation. Viewed from a business ethics standpoint, this is fair play, as the game of commerce is about negotiation from a position of power. However, as in the case of medical advocacy, it is clear that RT represents a grey frontier on which the ethical frameworks of business, Medicine, human rights, the West and the East dance to an unsteady rhythm.

Humbyrd suggests that we need to distinguish between harmful exploitation and mutually beneficial exploitation, and feels that RT is of the latter camp. ${ }^{10} \mathrm{He}$ concludes that the international surrogacy market needs to be regulated to ensure that the exploitation continues to be a mutually advantageous one.

\section{CONCLUSIONS}

Ethical questions around RT fall somewhere between the poles of autonomy and exploitation, essentially examining the extent to which a surrogate's freedom of choice justifies exposing her to risks, ${ }^{23}$ and the responsibilities of the client and clinician in ensuring an ethical transaction. ${ }^{24}$ The role of government is murky, ${ }^{24}$ though best manifests through legal restrictions on the industry. ${ }^{9}$ 
The most pressing concerns identified are the limits of informed consent and the uncertainty of independent advocacy enjoyed by the various stakeholders, the surrogate prime among them. The latter is an issue that can be readily addressed by law or by voluntary policy changes at the clinic level, or indeed by choice of the client, who can insist that any engaged surrogate be given independent counsel, the price of whom would be included in the client's package.

As the global RT industry expands, it is incumbent upon all parties, government and civil society included, to explore options for mitigating the many ethical challenges with which the phenomenon presents us.

\section{REFERENCES}

1. Ferraretti AP, Pennings G, Gianaroli L, et al. Cross-border reproductive care: a phenomenon expressing the controversial aspects of reproductive technologies. Reprod BioMed Online 2010;20:261-6.

2. Fontanella-Khan $\mathbf{A}$. India, the Rent-a-Womb Capital of the World: the country's booming 1market for surrogacy. Slate Magazine 23 Aug 2010. http://www.slate. com/id/2263136/

3. Brenhouse H. India's Rent-a-Womb Industry Faces New Restrictions. Time Magazine, USA. (Updated 5 Jun 2010; cited 1 Feb 2011). http://www.time.com/ time/world/article/0,8599,1993665,00.html

4. Nygren K, Adamson D, Zegers-Hochschild F, et al. Cross-border fertility care-International Committee Monitoring assisted reproductive technologies global survey: 2006 data and estimates. Fertil \& Steril 2010;94:e4-10.

5. Johnston J. The ethics of outsourcing surrogate motherhood to India. Medscape $J$ Med 2008;10:52.

6. Bardale R. Made in India? Ethics of outsourcing surrogate motherhood to India. Indian J Med Ethics 2009;6:56-7.

7. Qadeer I. Social and ethical basis of legislation on surrogacy: need for debate. Indian J Med Ethics 2009;6:28-31.

8. Parks JA. Care ethics and the global practice of commercial surrogacy. Bioethics 2010:24:333-40.
9. Pennings G, de Wert G, Shenfield F, et al. ESHRE Task Force on Ethics and Law 15: Cross-Border Reproductive Care. Hum Reprod 2008;23:2182-4.

10. Humbyrd C. Fair trade international surrogacy. Dev World Bioeth 2009:9:111-18.

11. Tieu MM. Altruistic surrogacy: the necessary objectification of surrogate mothers. $J$ Med Ethics 2009;35:171-5.

12. Widdows H. Localized past, globalized future: towards an effective bioethical framework using examples from population genetics and medical tourism. Bioethics 2011;25:83-91.

13. American Medical Association. (Homepage on the Internet). Patient Physician Relationship Topics: Informed Consent. (Updated 1995; cited 1 Feb 2011). http://bit. ly/MWSguk

14. Krogstad DJ, Diop S, Diallo A, et al. Informed consent in international research: the rationale for different approaches. Am J Trop Med Hyg 2010;83:743-7.

15. Gong G, Kosoko-Lasaki S, Haynatzki G, et al. Ethical, legal and social issues of genetic studies with African immigrants as research subjects. J Natl Med Assoc 2008:100:1073-7.

16. Lycett E. Surrogacy. In: Bentley G, Mace R, eds. Substitute Parents: Biological and Social Perspectives on Alloparenting in Human Societies. USA: Berghahn Books, 2009.

17. Hochschild A. Childbirth at the Global Crossroads. (Available on the Internet). The American Prospect. (Updated 5 Oct 2009; cited 1 Feb 2011). http://bit.ly/1GnVmK

18. Michigan Legislature. Surrogate Parenting Act (Act 199 of 1988). (Available on the Internet). Government of the State of Michigan. (Updated 198; cited 1 Feb 2011). http://1.usa.gov/PkGpSH

19. Ramasubramanian H. United Kingdom High Court rules on commercial surrogacy contracts. (Homepage on the Internet). Indian Surrogacy Law Centre. (Cited 1 Feb 2011). http://blog.indiansurrogacylaw.com

20. Min JK, Hughes E, Young D, et al. Joint Society of Obstetricians and Gynaecologists of Canada-Canadian Fertility and Andrology Society Clinical Practice Guidelines Committee: elective single embryo transfer following in vitro fertilization. J Obstet Gynaecol Can 2010;32:363-77.

21. Schieve LA, Meikle SF, Ferre C, et al. Low and very low birth weight in infants conceived with use of assisted reproductive technology. N Engl J Med 2002;346:731-7.

22. Hurst T, Shafir E, Lancaster P. Assisted conception Australia and New Zealand 1996. Assisted reproduction series no. 3. Sydney (AU): AlHW National Perinatal Statistics Unit, 1997.

23. Deech R. Reproductive tourism in Europe: infertility and human rights. Global Governance 2003;9:425-32.

24. Storrow RF. Quests for conception: fertility tourists, globalization, and feminist legal theory. Hastings Law J 2005;57:295-330.

25. Mulay S, Gibson E. Marketing of Assisted Human Reproduction and the Indian state. Development 2006:49:84-93. 